\title{
Burden of migraine in a Kuwaiti population: a door-to-door survey
}

\author{
Jasem Yousef Al-Hashel ${ }^{1,2^{*}}$, Samar Farouk Ahmed ${ }^{1,3}$ and Raed Alroughani ${ }^{4}$
}

\begin{abstract}
Background: Migraine prevalence and disability imprints on Kuwaiti population are underreported. We aimed to measure the prevalence of migraine and to assess its burden in Kuwait.

Methods: A cross-sectional community-based study was conducted which included biologically unrelated Kuwaiti adult population aged 18-65 years. They were randomly recruited from all six governments of Kuwait using stratified multistage cluster sampling. Trained interviewers visited the samples in door-to-door approach. The Headache-Attributed Restriction, Disability, and Social Handicap and Impaired Participation (HARDSHIP) questionnaire was used to collect the data. Demographic enquires were followed by diagnostic and disability questions.
\end{abstract}

Results: A total of 15,523 subjects were identified; of whom 3588 (23\%) were diagnosed as episodic migraine and 845 (5. $4 \%)$ as chronic headache. Prevalence of episodic migraine was $31.71 \%$ in female versus $14.88 \%$ in males $(P<0.01)$ with a mean age of $34.56 \pm 10.17$ years. Most of migraine cohort (64.4\%) sought medical advice with respect to their migraine headaches and the majority (62.4\%) were seen by general practitioners (GPs) while $17.2 \%$ were assessed by neurologists and $3.7 \%$ was seen by other specialties. Tension type headache and sinus-related headaches were diagnosed in $8.9 \%$ and $2.1 \%$ of migraine subjects respectively. The majority (94.6\%) of migraine subjects used symptomatic drugs for headache attacks, whereas 39.9\% were taking preventive medication. In the preceding 3 months to the survey, subjects with episodic migraine had lost a mean of 1.97 days from their paid work or school attendance compared to 6.62 days in chronic headache sufferers $(P<0.001)$. Additionally, subjects with episodic migraine lost a mean of 1.40 days from household work compared to 5.35 days in subjects with chronic headache $(P<0.001)$. Participants with episodic migraine and chronic headache missed a mean of 2.81 and 3.85 days on social occasions, in the preceding 3 months $(P<0.001)$.

Conclusions: Migraine in Kuwait is highly prevalent and it has a significant impact on activity of daily living, schooling/ employment and social occasions of patients. Accurate diagnosis, effective abortive and preventive treatments of migraine are paramount to improve quality of life and as well as cost saving.

Keywords: Epidemiology, Prevalence, Migraine, Burden, Kuwait

\section{Background}

Migraine prevalence is highest during the productive years of individuals between the ages of 25 and 55 [1]. Migraine may cause significant impact on activity of daily living including physical and emotional functions [2]. Global Burden of Disease Survey (GBD) 2010 [3] estimated that the global prevalence of migraine is approximately $15 \%$ and migraine was ranked as third most common diseases

\footnotetext{
* Correspondence: dralhashel@hotmail.com

${ }^{1}$ Neurology Department, Ibn Sina Hospital, P.O. Box 25427, 13115 Safat, Kuwait

${ }^{2}$ Faculty of Medicine, Kuwait University, P.O. Box 24923, 13110 Safat, Kuwait Full list of author information is available at the end of the article
}

in the world behind dental caries and Tension type headache (TTH). In 2013, migraine was recognized as the sixth-highest cause of disability in the world [4]. Migraine is a lifelong illness causing remarkable disability during the headache attacks, along with substantial financial burden to the patient as well as to the society. It also affects family and social relationships and impoverishes quality of life $[5,6]$. In approximately $2 \%$ of the population, a chronic form of migraine became more evident resulting in a significant impact on daily activities [7]. Migraine prevalence in Saudi Arabia, Qatar and Oman, is within the estimated worldwide prevalence range of $0.7-21.9 \%$ 
[8]. The lifetime migraine prevalence in the three Gulf countries was lower than in European studies, which report a range of $12-28 \%$ [9]. Migraine disability imprints on Kuwaiti population were underreported since the GBD2010 [2] and GBD2013 [3] estimation for migraine were derived from limited data extracted from hospital-based studies. Hence, our study aimed to assess the prevalence of migraine and its burden in Kuwait through a comprehensive approach utilizing a door-to-door survey. In a prior publication, we reported on prevalence of primary headache disorders. In the present study, we further report on the prevalence of episodic migraine stratified by age and gender, characters of migraine in addition to its burden, which was not shown in our previous published paper [10].

\section{Methods}

The full methodology was described elsewhere [10]. The fieldwork was carried out between January 2016 and April 2016. A population-based multistage random cluster sampling was conducted. Kuwaiti adults aged 18-65 years who were living in Kuwait for the last 6-month were identified. Adults who have deafness or major mental illness were excluded because of the communication difficulties with the interviewers. One adult member of each household was randomly selected after obtaining an informed consent. The interviewers consisted of 4 nurses and 10 medical students who were native Arabic speakers. The survey used several questionnaires such as Lifting The Burden (LTB) [11], Headache-Attributed Restriction, Disability, Social Handicap and Impaired Participation (HARDSHIP) questionnaire $[12,13]$ which were all translated into Arabic. Subjects were asked if all their headaches were of one or more types and, if more than one headache were identified, subsequent questions were focused on the one that was the most bothersome. The authors J.Y.A.-H. and S.F.A. established the diagnosis using an algorithm that was developed by LTB questionnaire [14] and based on ICD-II criteria [15]. Written informed consent was obtained from all the participants and they were free to decline participation at any time during the interviews.

\section{Data analysis}

Data of completed questionnaires were entered into SPSS version 20.0. Collected data was analyzed to assess 1-year prevalence for migraine headache as percentages with $95 \%$ confidence intervals (CIs). Prevalence of migraine was stratified by gender and age. Estimates both genders according to age categories (18-30, 31-40, 41-50 and 51-65) were calculated. Categorical variables were described in terms of frequency and proportions (\%, with 95\% CIs where appropriate), continuous variables in terms of means and standard deviations (SDs). We used chi-square to compare distributions between categorical variables and t-test to compare between numerical variables. We used Pearson's coefficient to test for correlation between continuous variables. We considered a $P$ value of $<0.05$ as statistically significant.

\section{Results}

The interviewers collected 16,332 questionnaires, of which 15,523 were complete and subsequently used for analysis. The participation rate was $53.26 \%$. The study sample presented $1.23 \%$ of the general population. A flowchart of the participants was published in our earlier paper [10]. Males represent $51.1 \%(n=7925)$ of the analyzed sample. The mean age of the overall sample was $37.51 \pm 11.82$ years.

Among the total respondents, $23.1 \%(n=3588)$ were diagnosed with episodic migraine while 5.4\% $(n=845)$ were diagnosed as chronic headache. The 1-year prevalence of episodic migraine was significantly higher in female $(31.71 \%)$ versus. Males $(14.88 \%) ; p<0.01$. The majority of the migraine population was female (67\%). The mean age of migraine subjects was significantly lower than subjects without migraine $(34.56 \pm 10.17$ vs. $41.67 \pm 12,94 ; p<0.01)$. On the other hand, females

Table 1 One-year prevalence of Episodic Migraine Headache stratified by age and gender

\begin{tabular}{|c|c|c|c|c|c|c|c|c|c|c|}
\hline \multirow{2}{*}{$\begin{array}{l}\text { Episodic Migraine } \\
\text { Age (years) }\end{array}$} & \multicolumn{3}{|l|}{ Total } & \multicolumn{3}{|l|}{ Male } & \multicolumn{3}{|l|}{ Female } & \multirow[t]{2}{*}{$P$} \\
\hline & $\begin{array}{l}\text { Participant } \\
\text { populations }\end{array}$ & $\begin{array}{l}\text { Migraine } \\
\text { cases }\end{array}$ & $\begin{array}{l}\text { Prevalence } \\
\% \text { (Cls 95\%) }\end{array}$ & $\begin{array}{l}\text { Participant } \\
\text { populations }\end{array}$ & $\begin{array}{l}\text { Migraine } \\
\text { cases }\end{array}$ & $\begin{array}{l}\text { Prevalence } \\
\% \text { (Cls 95\%) }\end{array}$ & $\begin{array}{l}\text { Participant } \\
\text { populations }\end{array}$ & $\begin{array}{l}\text { Migraine } \\
\text { cases }\end{array}$ & $\begin{array}{l}\text { Prevalence } \\
\% \text { (Cls 95\%) }\end{array}$ & \\
\hline $18-30$ & 5056 & 1382 & $\begin{array}{l}27.33 \\
(17.48-28.89)\end{array}$ & 2762 & 415 & $\begin{array}{l}15.05 \\
(6.06-16.44)\end{array}$ & 2294 & 967 & $\begin{array}{l}42.1 \\
(30.8-58.4)\end{array}$ & $0.001^{*}$ \\
\hline $31-40$ & 4997 & 1292 & $\begin{array}{l}25.86 \\
(17.36-72.19)\end{array}$ & 2433 & 431 & $\begin{array}{l}18.1 \\
(6.4-19.70)\end{array}$ & 2564 & 861 & $\begin{array}{l}32.93 \\
(18.3-64.3)\end{array}$ & $0.02^{*}$ \\
\hline $41-50$ & 3198 & 752 & $\begin{array}{l}23.54 \\
(22.10-25.05)\end{array}$ & 1511 & 327 & $\begin{array}{l}21.66 \\
(19.60-23.82)\end{array}$ & 1687 & 425 & $\begin{array}{l}25.18 \\
(23.12-27.32)\end{array}$ & 0.43 \\
\hline $51-65$ & 2272 & 162 & $\begin{array}{l}7.13 \\
(6.11-8.27)\end{array}$ & 1219 & 6 & $\begin{array}{l}0.5 \\
(0.13-1.3)\end{array}$ & 1053 & 156 & $\begin{array}{l}14.81 \\
(12.11-17.84)\end{array}$ & $0.001^{*}$ \\
\hline Total & 15,523 & 3588 & $\begin{array}{l}23.11 \\
(19.43-32.87)\end{array}$ & 7925 & 1179 & $\begin{array}{l}14.88 \\
(9.54-57.9)\end{array}$ & 7598 & 2409 & $\begin{array}{l}31.70 \\
(32.87-45.24)\end{array}$ & $0.01^{*}$ \\
\hline
\end{tabular}


with migraine were significantly younger than males with migraine ( $34.17 \pm 10.70$ vs. $35.43 \pm 8.92 ; p<0.01)$.

Table 1 shows the 1 -year prevalence of migraine headache stratified by age and gender. Migraine prevalence is based on the reported most bothersome headache. Age specific prevalence of episodic migraine was higher in age group 18-30 (27\%) compared to other age groups. Beyond 50 years of age, the prevalence fell in both genders (males: 0.5\%; females 14\%).

The characteristics of episodic migraine headache were summarized in Table 2. Mean days of headache in the last month in our study were 6.67 . The majority $(60 \%)$

Table 2 Character of episodic migraine headache among Kuwaiti populations $(N=3588)$

\begin{tabular}{|c|c|}
\hline Variables & $\mathrm{M} \pm \mathrm{SD} / \mathrm{No}(\%)$ \\
\hline Mean Age & $34.56 \pm 10.17$ \\
\hline \multicolumn{2}{|l|}{ Marital state } \\
\hline - Single & $641(17.9)$ \\
\hline - Married & $2738(67.3)$ \\
\hline - Divorced & $100(2.8)$ \\
\hline - Widow & $109(3)$ \\
\hline \multicolumn{2}{|l|}{ Education } \\
\hline - University & $2269(63.2)$ \\
\hline - High School & $1164(32.4)$ \\
\hline - Primary School & $17(0.4)$ \\
\hline \multicolumn{2}{|l|}{ Employment } \\
\hline - Full time & 2513(70) \\
\hline - Part time & $538(15)$ \\
\hline - Student & $170(4.7)$ \\
\hline • Housewife & $239(6.7)$ \\
\hline • Not working & $128(3.6)$ \\
\hline Frequency of attacks/month & $6.67 \pm 2.33$ \\
\hline Duration of attacks in hours & $6.08 \pm 334$ \\
\hline \multicolumn{2}{|l|}{ Severity of headache } \\
\hline - Not bad & $35(1.4)$ \\
\hline - Quite bad & $2170(60.4)$ \\
\hline - Very bad & $1369(38.2)$ \\
\hline \multicolumn{2}{|l|}{ Treatments taken } \\
\hline - Symptomatic treatment & 3395 (94.6) \\
\hline - Prophylactic treatment & $1433(39.9)$ \\
\hline Use Health service & $2309(64.4)$ \\
\hline \multicolumn{2}{|l|}{ Consultations } \\
\hline - General practitioner & $2253(62.8)$ \\
\hline - Neurologist & $616(17.2)$ \\
\hline - Persons prescribing Traditional Medicine & $586(16.3)$ \\
\hline - Other specialties & $81(2.3)$ \\
\hline
\end{tabular}

$M$ Mean, SD standard deviation had migraine headaches of moderate intensity. Most of migraine cohort (64.4\%) sought advice of health services. Most of the migraine headache patients $(62.4 \%)$ were seen by general practitioners (GPs) while neurologist, and other specialties saw $17.2 \%$ and $3.7 \%$ of patients respectively $(P<0.001)$. Only $4.6 \%$ of migraine cohort received a migraine diagnosis from a medical professional while, $8.9 \%$ was diagnosed as tension type headache and $2.1 \%$ were diagnosed as sinus headache. The majority $(94.6 \%)$ of migraine subjects used symptomatic drugs for their headache attacks during the past month, whereas $39.9 \%$ were taking preventive medication at the time of the survey.

There were significant positive correlations between both frequency of migraine attacks and lost days as shown in Table 3. The more frequent the attacks were, the more lost days observed in the preceding 3 months of the survey. However, the severity of attacks had only a negative impact on the social and family activities.

The cumulative number of lost days according to the HALT index was outlined in Table 4. Subjects with chronic headaches had a significantly higher burden. Subjects with episodic migraine had lost a mean of 1.97 days from their paid work or school attendance, versus 6.62 lost days in patients with chronic headache $(p<0.001)$. Similarly, subjects with episodic migraine lost a mean of 1.40 days from their household work versus 5.35 lost days in subjects with chronic headache $(p<0.001)$ in the preceding 3 months of the survey. Regarding social and family activities, subjects with episodic migraine and chronic headache missed mean of 2.81 and 3.85 days in the preceding 3 months of the survey $(P<0.001)$.

\section{Discussion}

The study captured data from all six governmental sectors of Kuwait. The 1-year prevalence of migraine in our study was $23 \%$, which was higher than previous studies conducted in Arab Gulf countries (Qatar 7.9\% [16] and in Oman 10.1\% [17]). Our result was similar to the prevalence for other international figures of $22 \%$ in Georgia [18], 25.2\% in Pakistan, [19], 20.8\% in Russia [20] 25.6 in India [21], 22.9\% in Zambia [22], and 29\% in Turkey [23]. On the other hand, our result was higher than that of the global estimate (14.7\%) [2] other countries such as Colombia (13.7\%) [24], Germany (18\%) [25] and China study $(9.3 \%)$ [26]. In Italy, migraine 1-year prevalence was $42.9 \%$; which is much higher than our result (5) and also the 1-year prevalence of migraine in Eurolight project 35.3\% [27] The discrepancies in the prevalence figures could be attributed to methodological differences, and to genetic, environmental or cultural factors. Our estimation of migraine prevalence in the 
Table 3 Impact of migraine attacks assessed by HALT questionnaire in preceding 3 months

\begin{tabular}{llll}
\hline Variables & Lost workdays & Lost housework days & Lost social and family days \\
\hline Frequency of attacks/month & $R=0.082$ & $R=0.125$ & $R=0.141$ \\
& $P=0.001^{*}$ & $P=0.001^{*}$ & $P=0.001^{*}$ \\
Severity of migraine attacks & $R=0.029$ & $R=0.022$ & $\mathbf{R}=0.047$ \\
& $P=0.098$ & $P=0.181$ & $P=0.005^{*}$ \\
\hline
\end{tabular}

HALT índex headache-attributed lost work, housework and social days

* Significant $P$ Value

Kuwaiti population is matching to our previous estimation of migraine among medical students (27.9\%) [28]. Our study reported a female preponderance of $67 \%$ that could be hormonally determined which is consistent with previous studies [29].

More than $38 \%$ of migraine subjects were younger than 30 years of age and approximately $68 \%$ were in the age group between 18 to 50 years of age similar to previous published studies $[19,20,23]$. The highest age specific prevalence of episodic migraine in our cohort is $27.3 \%$ in the age group 18-30 years and the lowest prevalence is in the age group 51-65 years. Prevalence of migraine in females is high in the 18-30 age group and middle age group (31-40 years) but sharply declined in the postmenopausal age group (51-65 years), which is similar to previous reports [20,24]. These trends can be attributed to the well-documented influence on migraine of estrogen levels [29]. However migraine prevalence declined also in our male cohorts older than 50 years.

Most of migraine cohort sought medical advice for their headaches. Although the majority was seen by their GPs, only $4.6 \%$ received accurate diagnosis of migraine. A study conducted in the UK [30] indicated that $70 \%$ of migraine headache patients were not given a diagnostic label, by GPs. It was suggested that GPs' difficulty in diagnosing migraine headache presentations results in increase in the impact of migraine headaches on activity of daily living. [31]. Interestingly, in our study, migraine cohort showed that seeking traditional Arab treatment, like; Hijama is nearly equal to seeking neurologist. A significant number of our population continues to believe in this type of treatment, which is performed by nonmedical personnel. The community awareness with migraine needs to be improved and the education of the

Table 4 Impact of episodic migraine versus chronic headache assessed by HALT questionnaire in preceding 3 months

\begin{tabular}{llll}
\hline Variables & Episodic Migraine & Chronic Headache & $P$ value \\
& $\mathrm{M} \pm \mathrm{SD}$ & $\mathrm{M} \pm \mathrm{SD}$ & \\
\hline Work days & $1.87 \pm 1.71$ & $6.62 \pm 2.41$ & $0.001^{*}$ \\
Housework days & $1.44 \pm 1.83$ & $5.35 \pm 2.36$ & $0.001^{*}$ \\
Social and family days & $2.81 \pm 1.75$ & $3.85 \pm 2.95$ & $0.001^{*}$ \\
\hline
\end{tabular}

HALT index headache-attributed lost work, housework and social days, $M$ Mean, $S D$ standard deviation

*Significant $P$ Value primary care providers is an important step in this aspect to limit the numbers of under-diagnosed or misdiagnosed patients. This high percentage of patients who sought medical advice reflects the impact of migraine on health resources. Previous studies reported that headache was one of the highest indications seen by general practitioners and neurologists [32,33]. A survey of neurologists indicated that up to a third of all their referral were related to headaches [34]. We reported that $94.6 \%$ of our cohort had used acute medication, which was nearly similar to an Austrian study, which reported that 94.4\% had used acute abortive medications. Similarly, the proportion of patients who used prophylactic medication in our study (39.9\%) was comparable to the Austrian study (34\%) [35].

Despite the significant burden of migraine in different countries, the impact of migraine on daily activities was poorly described in Kuwait. We reported that subjects with episodic migraine lost an average 1.8 days from their paid work in the preceding 3 months to the survey, which was nearly similar to an Italian study of 2.3 lost days [5] and Eurolight project that reported mean lost workdays about 1 day/ month [27]. The frequency of migraine attacks in our cohort was significantly correlated with missing working, school and social days, and household activities during their migraine attack. Our results were in line with previous findings of a direct correlation between attack frequency and migrainerelated disability for people with migraine [36].

Social activity and work capacity were reduced in almost all people with migraine [37]. Our results reported chronic headache in $5.4 \%$ of the total cohort. We demonstrated that the rate of disability days per month (using HALTquestionnaire) was significantly higher in chronic headache participants compared to episodic migraine participants. This is consistent with previous studies [35, 36, 38-40]. Thus, chronic headache participants were less able to perform work and leisure activities than those with episodic migraine participants. Chronic headache might affect family and social life along with employment $[37,38]$.

Since migraine is most troublesome in the productive years, its public health importance lies in its causal association with these personal and societal burdens of pain, disability, damaged quality of life and financial cost [40]. Many 
governmental and nongovernmental stakeholders do not recognize that the direct costs of migraine management is smaller when compared with the large indirect-cost savings that might be made from reducing lost working days, school days, social activities [5, 26, 41, 42].

One major limitation that needs to be outlined is the sampling methodology. Although we propose a probability sample method (cluster sampling), it is not adjusted for gender and age according to the participation of the Kuwaiti population; hence it may not entirely reflect the distribution of the whole population. To minimize this potential source of bias, we used a large sample.

Another limitation was the recall bias, which is usual in most of the studies using questionnaire. On the other hand, this study is the first and largest population-based survey in Kuwait to estimate the prevalence of migraine headache, and the first to measure migraine-attributed burden.

\section{Conclusions}

Migraine is prevalent in Kuwait and has a significant socioeconomic burden especially in its chronic form. Improving the public awareness of migraine through health education of primary care providers and public media may reduce the misdiagnosis and subsequently result in better quality of life and reduce the economic burden.

\section{Abbreviations}

Cls: Confidence intervals; GBD: Global Burden of Disease Survey; GPs: General practitioners; HALT: Headache-Attributed Lost Time Index questionnaire; HARDSHIP: Headache-Attributed Restriction, Disability, Social Handicap and Impaired Participation questionnaire; LTB: Lifting The Burden; SDs: Standard deviations; $T \mathrm{TH}$ : Tension type headache

\section{Acknowledgements}

We would like to thank the study participants and the nurses for actively participating.

\section{Funding}

This study was partly funded by scientific grant from Kuwait University, Research Sector.

\section{Authors' contributions}

JA was the project leader and contributed to project design and development of the methodology, SA: contributed to project design and development of the methodology, data acquisition and statistical analysis and drafted the manuscript. RA revised the manuscript critically. All authors read and approved the final manuscript.

\section{Ethics approval and consent to participate}

The faculty of Medicine, Kuwait University approved the study. The project tittle is MM02/15.

\section{Competing interest}

The authors declare that they have no competing interests.

\section{Publisher's Note}

Springer Nature remains neutral with regard to jurisdictional claims in published maps and institutional affiliations.

\section{Author details}

${ }^{1}$ Neurology Department, Ibn Sina Hospital, P.O. Box 25427, 13115 Safat, Kuwait. 'Faculty of Medicine, Kuwait University, P.O. Box 24923, 13110 Safat, Kuwait. ${ }^{3}$ Neuropsychiatry department, Faculty of Medicine, Al-Minia University, P.O. Box 61519, Minia City, Minia 61111, Egypt. ${ }^{4}$ Division of Neurology, Department of Medicine, Amiri Hospital, Sharq, Kuwait.

Received: 16 July 2017 Accepted: 30 September 2017

Published online: 13 October 2017

\section{References}

1. Burch RC, Loder S, Loder E, Smitherman TA (2015) The prevalence and burden of migraine and severe headache in the United States: updated statistics from government health surveillance studies. Headache 55:21-34

2. Leonardi M, Steiner TJ, Scher AT, Lipton RB (2005) The global burden of migraine: measuring disability in headache disorders with WHO's classification of functioning, disability and health (ICF). Journal of headache and Pain 6:429-440

3. Vos T, Flaxman AD, Naghavi M, Lozano R, Michaud C, Ezzati M, Shibuya K, Salomon JA, Abdalla S, Aboyans V, Abraham J, Ackerman I, Aggarwal R, Ahn SY, Ali MK, Alvarado M, Anderson HR, Anderson LM, Andrews KG, Atkinson C, Baddour LM, Bahalim AN, Barker-Collo S, Barrero LH, Bartels DH, Basáñez MG, Baxter A, Bell ML, Benjamin EJ, Bennett D et al (2012) Years lived with disability (YLDs) for 1160 sequelae of 289 diseases and injuries 1990-2010: a systematic analysis for the global burden of disease study 2010. Lancet 380: 2163-2196

4. Global Burden of Disease Study 2013 Collaborators Global, regional, and national incidence, prevalence, and years lived with disability for 301 acute and chronic diseases and injuries in 188 countries, 1990-2013: a systematic analysis for the global burden of disease study 2013 (2015). Lancet 386(9995):743-800

5. Allena M, Steiner TJ, Sances G, Carugno B, Balsamo F, Nappi G, Andrée C, Tassorelli C (2015) Impact of headache disorders in Italy and the publichealth and policy implications: a population-based study within the Eurolight project. J Headache Pain 16:100

6. $\mathrm{WHO}$, Lifting the burden (2011). Atlas of headache disorders and resources in the world 2011. http://www.who.int/mental_health/management/atlas_ headache_disorders/en/_headache_disorders/en/

7. Manack AN, Buse DC, Lipton RB (2011) Chronic migraine: epidemiology and disease burden. Curr Pain Headache Rep 15:70-78

8. Scher Al, Stewart WF, Lipton RB (1999) Migraine and headache: a metaanalytic approach. In: Crombie IK (ed) Epidemiology of pain; IASP press, WA, pp 159-170

9. Stovner LJ, Zwart JA, Hagen K, Terwindt GM, Pascual J) (2006). Epidemiology of headache in Europe. Eur J Neurol; 13:333-345

10. Al-Hashel J, Ahmed SF, Alroughani R (2017) Prevalence of primary headache disorders in Kuwait. Neuroepidemiology 48:138-146

11. Steiner TJ, Birbeck GL, Jensen R, Katsarava Z, Martelletti P, Stovner LJ (2011) The global campaign, World Health Organization and lifting the burden: collaboration in action. Journal of headache and Pain 12:273-274

12. Steiner TJ, Lifting the burden (2005) The global campaign to reduce the burden of headache worldwide. J Headache Pain 6:373-377

13. Steiner TJ, Gururaj G, Andrée C, Katsarava Z, Ayzenberg I, SY Y, Al Jumah M, Tekle-Haimanot R, Birbeck GL, Herekar A, Linde M, Mbewe E, Manandhar K, Risal A, Jensen R, Queiroz LP, Scher Al, Wang SJ, Stovner LJ (2014) Diagnosis, prevalence estimation and burden measurement in population surveys of headache: presenting the HARDSHIP questionnaire. J Headache Pain. 15:30

14. Steiner TJ (2004) Lifting the burden: the global campaign against headache. Lancet Neurol 3:204-205

15. Headache Classification Subcommittee of the International Headache Society: The international classification of headache disorders, ed 2. Cephalalgia 2004; 24(suppl 1):9-160

16. Bener A (2006) Frequency of headache and migraine in Qatar. Neuroepidemiology 27:61-66

17. Deleu D, Khan MA, Al Shehab TA (2002) Prevalence and clinical characteristics of headache in a rural community in Oman. Headache 42:963-973

18. Katsarava Z, Kukava M, Mirvelashvili E, Tavadze A, Dzagnidze A, Djibuti M, Steiner TJ (2007) A pilot methodological validation study for a population based survey of the prevalence of migraine, tension -type headache and chronic daily headache in the country of Georgia. J Headache Pain 8:77-82 
19. Herekar AA, Ahmad A, Uqaili UL, Ahmed B, Effendi J, Alvi SZ, Shahab MA, Javed U, Herekar AD, Khanani R, Steiner TJ (2017) Primary headache disorders in the adult general population of Pakistan - a cross sectional nationwide prevalence survey. J Headache Pain 18:28

20. Ayzenberg I, Katsarava Z, Sborowski A, Chernysh M, Osipova V, Tabeeva G, Yakhno N, Steiner TJ (2012) The prevalence of primary headache disorders in Russia: a countrywide survey. Cephalalgia 32:373-381

21. Kulkarni GB, Rao GN, Gururaj G, Stovner LJ, Steiner TJ (2015) Headache disorders and public ill-health in India: prevalence estimates in Karnataka state. J Headache Pain 16:67

22. Mbewe E, Zairemthiama P, Yeh HH, Paul R, Birbeck GL, Steiner TJ (2015) The epidemiology of primary headache disorders in Zambia: a population-based door-to-door survey. J Headache Pain 16(1):515

23. Ertas M, Baykan B, Orhan EK, Zarifoglu M, Karli N, Saip S, Onal A, Siva A (2012) One-year prevalence and the impact of migraine and tension-type headache in Turkey: a nationwide home-based study in adults. J Headache Pain 13:147-157

24. Rueda-S.nchez M, d az-Martnez LA (2008) Prevalence and associated factors for episodic and chronic daily headache in the Colombian population. Cephalalgia 28(3):216-225

25. Yoon MS, Katsarava Z, Obermann M, Fritsche G, Oezyurt M, Kaesewinkel K, Katsarova A, Santowski I, Diener H, Moebus S (2012) Prevalence of primary headaches in Germany: results of the German headache consortium study. $J$ Headache Pain 13:215-223

26. Yu S, Liu R, Zhao G, Yang X, Qiao X, Feng J, Fang Y, Cao X, He M, Steiner T (2012) The prevalence and burden of primary headaches in China: a population-based door-to-door survey. Headache 52:582-591

27. Steiner TJ, Stovner LJ, Katsarava Z, Lainez JM, Lampl C, Lantéri-Minet M, Rastenyte D, Ruiz de la torre E, Tassorelli C, Barré J, Andrée C (2014) The impact of headache in Europe: principal results of the Eurolight project. The Journal of Headache and Pain 15:31

28. Al-Hashel JY, Ahmed SF, Alroughani R, Goadsby PG (2014) Migraine among medical students in Kuwait University. The Journal of Headache and Pain 15:26

29. Brandes $J L$ (2006) The influence of estrogen on migraine: a systematic review. JAMA 295:1824-1830

30. Kernick D, Stapley S, Hamilton W (2008) GPs' classification of headache: is primary headache under diagnosed? Br J Gen Pract 58:102-104

31. World Health Organization (2004) Headache disorders. In: Fact sheet $N^{\circ} 277$ Accessed on 28 June 2010

32. Schwartz BS, Stewart WF, Lipton RB (1997) Lost workdays and decreased work effectiveness associated with headache in the workplace. J Occup Environ Med 39:320-327

33. Hopkins A, Menken M, De Friese GA (1989) A record of patient encounters in neurological practice in the United Kingdom. Journal of Neurology Neurosurgery and Psychiatry 52:436-438

34. Laughey WF, Holmes WF, Mac Gregor AE, Sawyer JPC (1999) Headache consultation and referral patterns in one UK general practice. Cephalalgia 19:328-329

35. Zebenholzer K, Andree C, Lechner A, Broessner G, Lamp C, Luthringshausen G, Wuschitz A, Obmann SM, Berek K, Wöber C (2015) Prevalence, management and burden of episodic and chronic headaches-a crosssectional multicentre study in eight Austrian headache centers. The Journal of Headache and Pain 16:46

36. Bigal ME, Rapoport AM, Lipton RB et al (2003) Assessment of migraine disability using the migraine disability assessment (MIDAS) questionnaire: a comparison of chronic migraine with episodic migraine. Headache 43:336-342

37. Lipton RB, Bigal ME, Kolodner K, Stewart WF, Liberman JN, Steiner TL (2003) The family impact of migraine: population-based studies in the US and UK. Cephalalgia 23:429-440

38. Buse DC, Manack AN, Serrano D, Varon SF, Turkel LRB (2012) Headache impact of chronic and episodic migraine: predictors of impact from the American migraine prevalence and prevention (AMPP) study. Headache 52(1):3-17

39. Bigal ME, Serrano D, Reed M et al (2008) Chronic migraine in the population: burden, diagnosis, and satisfaction with treatment. Neurology 71:559-566

40. Adams AM, Serrano D, Buse DC, Reed ML, Marske V, Fanning KM, Lipton RB (2015) The impact of chronic migraine: the chronic migraine epidemiology and outcomes (CaMEO) study methods and baseline results. Cephalalgia; Vol 35(7):563-578

41. Le H, Tfelt-Hansen P, Skytthe A, Kyvik KO, Olesen J (2011) Association between migraine, lifestyle and socioeconomic factors: a populationbased cross-sectional study. Journal of headache and Pain 12:157-172

42. Stovner LJ, Hagen K (2006) Prevalence, burden, and cost of headache disorders. Curr Opin Neurol 19:281-285

\section{Submit your manuscript to a SpringerOpen ${ }^{\circ}$ journal and benefit from:}

- Convenient online submission

- Rigorous peer review

- Open access: articles freely available online

- High visibility within the field

- Retaining the copyright to your article

Submit your next manuscript at $\boldsymbol{\nabla}$ springeropen.com 